The call for RA stories received a fantastic response from the public and the reading panel had a tough job in selecting the contributions which would feature in the published volume. Once the successful contributions were chosen, Arthritis Ireland proceeded to design a book, which could be sold in the book trade and online.

Results: In September 2019, Arthritis Ireland published My RA Story: Personal accounts of living with rheumatoid arthritis. Launched in the National Library of Ireland by Sinead Moriarty, the 46 contributions touched upon themes of pain, fatigue, emotional impact, disability, surgery, education, career, family, goal-setting, self-management, connecting with others, hope, etc.

The contributors came from people who were living with RA for over 40 years, as well as from those who were more recently diagnosed.

The book is a hugely valuable contribution to health literature. Arthritis Ireland now plans to make the book available for sale internationally, through Amazon and other retail channels, as well as promoting it more extensively in rheumatology clinics.

In October, one of the contributors was interviewed on national television about her RA story, as part of a feature on World Arthritis Day.

Conclusion: This campaign gave people living with RA a platform to write about and share about their condition. Fronted by an RA champion with significant name recognition and an enormous audience in her own right, best-selling author, Sinéad Moriarty, the book, My RA Story. Crucially, the book is a valuable resource for people who are newly diagnosed with the disease and uncertain of what the future holds.

Acknowledgments: This project was supported by an educational grant from MSD.

Disclosure of Interests: Brian Lynch Grant/research support from: Arthritis Ireland received a grant from MSD to develop this patient education programme. Brian Lynch has not benefited personally in any way. DOI: 10.1136/annrheumdis-2020-eular.6466

\section{PARE0004 PATIENT PERSPECTIVE ON THE EFFICACY AND RISKS OF GLUCOCORTICOIDS IN RHEUMATOID ARTHRITIS - AN INTERNATIONAL SURVEY OF 1344 PATIENTS}

T. Santiago ${ }^{1,2}$, M. Voshaar $^{3}$, M. De Wit ${ }^{4}$, P. Carvalho, ${ }^{5,6,7}$, F. Buttgereit ${ }^{8}$, M. Cutolo ${ }^{9}$, M. Boers ${ }^{10}$, J. A. P. Da Silva ${ }^{1,2} .^{1}$ Centro Hospitalar e Universitário de Coimbra, Rheumatology Department, Coimbra, Portugal; ${ }^{2}$ University of Coimbra, Faculty of Medicine, Coimbra, Portugal; ${ }^{3}$ University of Twente, Department of Psychology, Health and Technology, Enschede, Netherlands and Stichting Tools Patient Empowerment, Amsterdam, Netherlands; ${ }^{4}$ Stichting Tools Patient Empowerment, Amsterdam, Netherlands; ${ }^{5}$ Department of Rheumatology, Centro Hospitalar Universitário do Algarve, Faro, Portugal; ${ }^{6}$ Lisbon Academic Medical Centre, Lisbon, Portugal; ${ }^{7}$ Algarve Biomedical Center, Faro, Portugal; ${ }^{8}$ Department of Rheumatology and Clinical Immunology, Charité University Medicine Berlin, Berlin, Germany; ${ }^{9}$ Research Laboratory and Academic Division of Clinical Rheumatology, Department of Internal Medicine, University of Genova, IRCCS Polyclinic Hospital San Martino, Genova, Italy; ${ }^{10}$ Department of Epidemiology and Biostatistics; and Amsterdam Rheumatology and immunology Center, Amsterdam University Medical Centers, Vrije Universiteit, Amsterdam, Netherlands

Background: The Glucocorticoid Low-dose Outcome in Rheumatoid Arthritis Study (GLORIA) is an international investigator-initiated pragmatic randomized trial designed to study the effects of low-dose glucocorticoids (GCs) in elderly patients with Rheumatoid Arthritis (RA).

The research team is also committed to promote a better understanding of the risks and benefits of these drugs among health professionals and patients. In order to achieve these goals, it is important to assess the current ideas and concerns of patients regarding GCs.

Objectives: To evaluate the current patient perspective on the efficacy and risks of GCs in RA patients who are or have been treated with GCs.

Methods: Patients with RA completed an online survey (with 5 closed questions regarding efficacy and safety) presented in their native language. RA patients were recruited through a variety of patient organizations representing three continents. Patients were invited to participate through national patient organizations. In the USA, patients were also invited to participate through MediGuard. org. Participants were asked for their level of agreement on a 5-point Likert scale.

Results: 1344 RA patients with exposure to GCs, from Brazil, USA, UK, Portugal, Netherlands, Germany and 24 other countries ${ }^{\star \star}$ participated: $89 \%$ female, mean age (SD) 52 (14) years and mean disease duration 13 (11) years. The majority of participants (84\%) had $\geq 10$ years of education. The duration of GCs exposure was $1.6(4.2)$ years. The majority of participants had read articles or pamphlets on the benefits or harms of GC therapy.
Regarding GCs efficacy (table 1), high levels of endorsement were found: about $2 / 3$ of patients considered that GCs as very useful in their case, more than half considered that GCs were effective even at low doses, and agreed that GC improved RA symptoms within days.

Regarding safety (table 1), 1/3 of the participants reported having suffered some form of serious adverse events (AEs) due to GCs, and $9 \%$ perceived this as "life-threatening. Adverse events had a serious impact on quality of life, according to about $1 / 3$ of the respondents.

Conclusion: Patients with RA exposed to GC report a strong conviction that GCs are very useful and effective for the treatment of their RA, even at low doses. This is accompanied by an important prevalence of serious AEs. Understanding the patient perspective can improve shared decision-making between patient and rheumatologist.

References: Funding statement: This project has received funding from the European Union's Horizon 2020 research and innovation programme under grant agreement No 634886 .

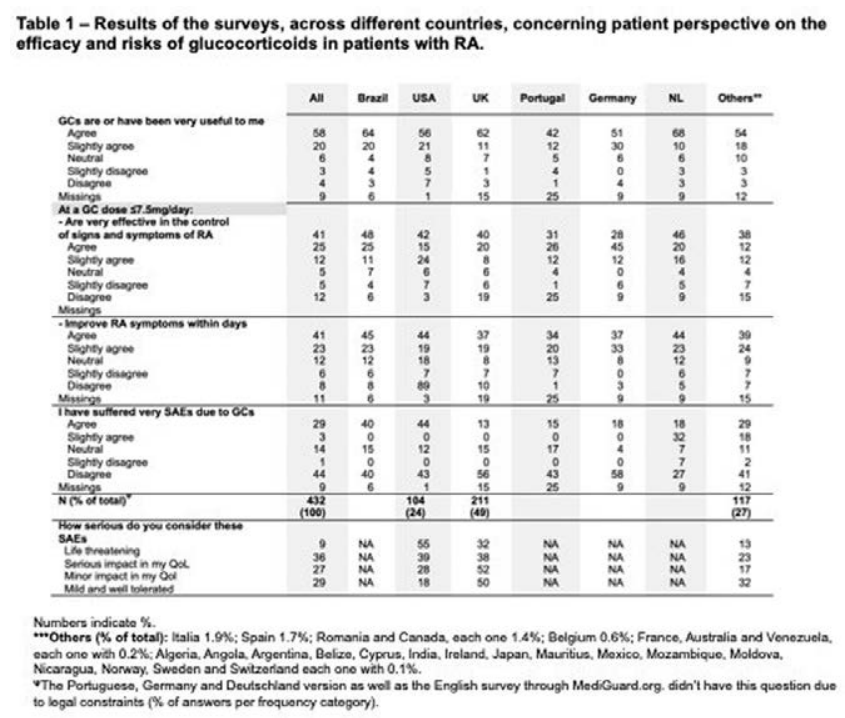

Disclosure of Interests: Tânia Santiago: None declared, Marieke Voshaar Grant/ research support from: part of phd research, Speakers bureau: conducting a workshop (Pfizer), Maarten de Wit Grant/research support from: Dr. de Wit reports personal fees from Ely Lilly, 2019, personal fees from Celgene, 2019, personal fees from Pfizer, 2019, personal fees from Janssen-Cilag, 2017, outside the submitted work., Consultant of: Dr. de Wit reports personal fees from Ely Lilly, 2019, personal fees from Celgene, 2019, personal fees from Pfizer, 2019, personal fees from Janssen-Cilag, 2017, outside the submitted work., Speakers bureau: Dr. de Wit reports personal fees from Ely Lilly, 2019, personal fees from Celgene, 2019, personal fees from Pfizer, 2019, personal fees from Janssen-Cilag, 2017, outside the submitted work., Pedro Carvalho: None declared, Frank Buttgereit Grant/research support from: Amgen, BMS, Celgene, Generic Assays, GSK, Hexal, Horizon, Lilly, medac, Mundipharma, Novartis, Pfizer, Roche, and Sanofi., Maurizio Cutolo Grant/research support from: Bristol-Myers Squibb, Actelion, Celgene, Consultant of: Bristol-Myers Squibb, Speakers bureau: Sigma-Alpha, Maarten Boers: None declared, José Antonio P. da Silva Grant/research support from: Pfizer, Abbvie, Consultant of: Pfizer, AbbVie, Roche, Lilly, Novartis DOI: 10.1136/annrheumdis-2020-eular.3164

\section{PARE0005 \\ INTEGRATED REFERRAL OF NEWLY DIAGNOSED RHEUMATOID ARTHRITIS PATIENT TO EDUCATION AND SUPPORT RESOURCES DELIVERED BY PATIENT LED ORGANISATION}

I. Mcnicol ${ }^{1}$, A. Bosworth ${ }^{1}$, C. Jacklin ${ }^{1}$, J. Galloway ${ }^{2}$ on behalf of Ailsa Bosworth MBE, James Galloway, Clare Jacklin. ${ }^{1}$ National Rheumatoid Arthritis Society, Maidenhead, United Kingdom; ${ }^{2}$ King's College Hospital, London, United Kingdom

Background: NRAS follows best practice, evidence-based standards in all we do. Whilst huge strides have been made in the diagnosis and treatment of RA, the impact on quality of life can be significant and for many this disease remains hard to come to terms with. NRAS services and resources can improve the outcomes of people with RA/Adult JIA through a framework of supported self-management resources tailored to individual need. It is particularly important to provide the right support at the beginning of a person's journey with RA, when unhelpful health beliefs, anxiety and incorrect information can influence how someone responds to prescribed 